\title{
THE DEVELOPMENT OF 1080 USE FOR RABBIT CONTROL IN TASMANIA
}

\author{
by M. Statham
}

(with one text-figure and two tables)

\begin{abstract}
Statham, M. 2005 (16:xii): The development of 1080 use for rabbit control in Tasmania. Papers and Proceedings of the Royal Society of Tasmania 139: 1-6. https://doi.org/10.26749/rstpp.139.1 ISSN 0080-4703. Tasmanian Institute of Agricultural Research, PO Box 46, Kings Meadows, Tasmania 7249, Australia.

The Tasmanian Department of Agriculture, together with the CSIRO Wildlife Survey Section pioneered the use of sodium fluoroacetate (Compound 1080) in Australia following reports of experimental trials in the USA. This paper, with information taken primarily from Department of Agriculture files, describes the development of 1080 use in Tasmania from 1949 to the last major effect on practices in other states in 1964.
\end{abstract}

Key Words: 1080, rabbit, sodium fluoroacetate, Tasmania, history.

\section{INTRODUCTION}

Compound 1080 has a controversial history in Tasmania, as it is often used to control native macropods and brush-tailed possums. These species have increased dramatically in numbers since the 1960 s as a result of agricultural development. In response to public opposition to its use, the Government adopted a plan to reduce the level of 1080 use with a phase out by 2015 (Community Leaders Group 2001), and on 22 September 2004 the Premier of Tasmania, Paul Lennon, announced there would be a ban on 1080 use in State forests by December 2005 (Examiner 23 September 2004). Tasmania is the first state to make this decision, which represents a long-term change in government and public thinking.

The early history of the discovery and development of sodium monofluoroacetate (Compound 1080) in Europe has been described by a number of authors, including Ward (1946), Atzert (1971) and Connolly (2004). Prior to the Second World War most rodenticides were produced in Europe and the beginning of the war led to a chemical screening program to develop new rat and mouse control agents for use in the USA. One of the most promising chemicals found during this evaluation was Compound 1080. In order to protect use of the material by the US government and to ensure that the compound could not be patented by anyone other than the researcher involved, the rodenticidal properties of 1080 and its effects on a number of other species including dogs were described by Kalmbach (1945) (cited by Connolly 2004). Other groups were working on this and related compounds (e.g., McCombie \& Saunders 1946), and the effects of 1080 on a range of other species were soon reported (Ward 1946, Ward \& Spencer 1946, King \& Penfound 1946). Because of its toxicity and lack of taste, an approach was made to the manufacturer, Monsanto, to restrict sales and ensure the chemical would be shipped only to "responsible" users (Connolly 2004). Despite this, it wasn't long before accidental poisonings of humans (Williams 1948) and domestic animals (Nichols et al. 1949) were reported.

\section{THE TASMANIAN SITUATION}

Rabbits in higher rainfall areas have better survival of young in dry years (Williams et al. 1995) so it is not surprising that in Tasmania in the late 1940s rabbits were in high numbers following a dry period (fig. 1). Both Oatlands, in the central wool-growing area of the state, and Wilmot in the higher rainfall northwest, as well as other areas, were suffering from significant rabbit problems at the time.

The poisons then used, strychnine and phosphorus (as a phosphorus-pollard mix), killed only $60-70 \%$ of rabbits leaving adequate numbers for the next breeding season. There also was a shortage of fumigants for destroying rabbits in burrows, further limiting control options (memo from A.E. Hughes, Senior Stock Inspector to G.K. Meldrum, Acting Chief Veterinary Officer, May 1949, TGAM).

At this time rabbit control was carried out under the provisions of The Rabbit Destruction Act 1889, under which the power to enforce rabbit destruction was vested in local government. Councils were able to raise rates and employ inspectors for the purpose of implementing the Act. The Department of Agriculture had the authority to assume a council's responsibility for rabbit control if, in the opinion of the head of the Department, a council was not complying adequately with the legislation. In practice the Department of Agriculture did not have staff to assume this role and even in the case of councils which did not control rabbits it was not possible for the Department of Agriculture to take effective action. Given the high rabbit numbers in the state in 1949 the Act was seen to have

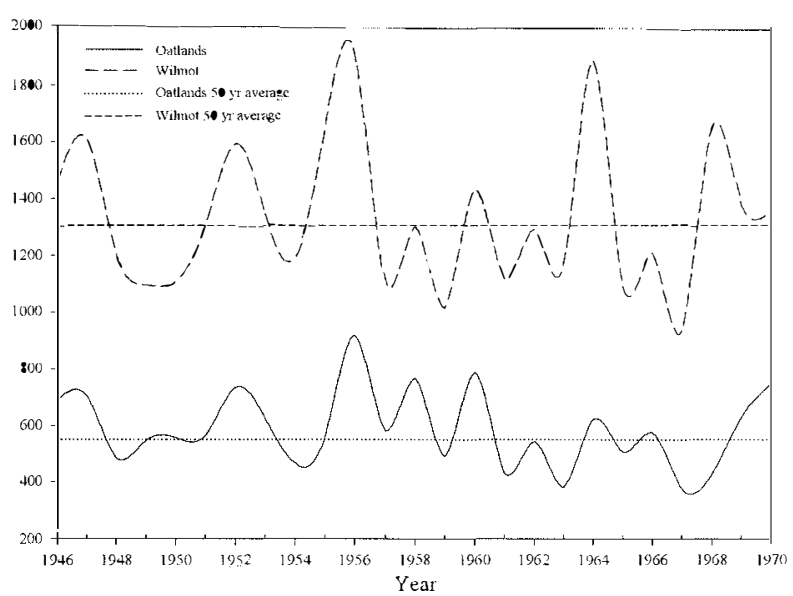

FIG. 1 - Rainfall at two sites in Tasmania, 1946-70 (data from Barnes-Keoghan 2002). 
failed in its aim and Parliament initiated a review of the functions of the rabbit control authorities (Meldrum 1959). A new Act, The Vermin Destruction Act 1950, transferred power over rabbit control from local government to the Secretary for Agriculture. It also widened the definition of a landholder to include public instrumentalities and the Crown, and rabbit control on any leased land, whether Government or privately owned, became the responsibility of the lessee. In addition, the Secretary of Agriculture could order departmental staff to carry out rabbit control at the owner's expense if the owner did not comply with the orders given by a rabbit inspector.

With the passing of The Vermin Destruction Act the Department of Agriculture established a Vermin Control Section of 16 district inspectors and three mobile teams of two men, all under the control of a Senior Vermin Officer (Alan Hughes). The detailed administrative control was carried out by the Chief Veterinary Officer, Keith Meldrum (Meldrum 1959). The mobile teams were equipped with a Land Rover and caravan and, if required, a tractor. The majority of their work was in response to requests for assistance with routine rabbit control, but they also spent considerable time working on land owned by government agencies (Hughes 1959). They camped where they were working, sometimes for weeks at a time (D. Brooks pers. comm.), and the landowner was charged for the cost of labour and materials used by them.

The search for improved techniques was started in May 1949 when Alan Hughes wrote to Keith Meldrum suggesting there was scope for improvement of destruction methods and asking him to request the CSIR to conduct research on poisons and methods of poisoning rabbits, and particularly for information on strychnine poisons that could be laid with a poison cart (TGAM). The concept of a new poison may well have been stimulated by a report of a talk to the Victorian Chamber of Agriculture by Francis Ratcliffe, leader of the CSIR Wildlife Survey Section (Advocate 28 February 1949). He suggested that poisons developed during the war were likely to be better than those then being used but it was first necessary to learn more about the rabbit, and satisfactory poisoning measures would be applied eventually. Ratcliffe's comments on poisoning came at a time when myxomatosis trials carried out in his section were having very poor results with the disease not spreading and appearing to be a failure (Rolls 1969).

In June 1949 Keith Meldrum wrote to ICI in Sydney asking for information on the rodent poison sodium monofluoroacetate about which he had read in recent years. Later in the month Alan Hughes wrote again pointing out that in the north of the state, the demand for poisons and fumigants had exhausted all supplies with the exception of strychnine. As Eberhard \& Co., the manufacturers of "Gisko" phosphorus poison bait in Launceston, still had not had a reply from the Prices Commissioner to their application for an increase in price they were not releasing any poison. Even when the new price was approved, Eberhard $\&$ Co. could not source enough high-quality pollard locally to meet the demand for poison, and Alan Hughes requested that the Department of Agriculture make representation to Gibson's Mill in Hobart for the supply of one ton of pollard a week to Eberhard \& Co. Meldrum replied that the Wheat Board claimed that pollard was in very short supply throughout the state and therefore no extra allocation could be made from Hobart (TGAM).

In early August 1950 Meldrum, then the Chief Veterinary
Officer, sent a memo to Hughes to say that he had received a reply from ICI and they had obtained information on Compound 1080 for him from the CSIR. He saw the problems being the toxicity to humans and domestic animals and the prohibitive cost, with a recent purchase by the Director of Health in Canberra being $£ 6 / 7 /$ - per pound with one ounce being sufficient to make only 28 pounds of bait. Also, the Commonweal th would only allow its importation and use by departmental officers whose function was solely the destruction of vermin. This restriction would change poisoning practices, because strychnine and phosphorus were freely available and farmers could carry out rabbit control with no government involvement. He ended by recommending against experiments at that time. The argument did not seem to convince Hughes, as within a week he replied pointing out that strychnine was also highly poisonous and the odourless, tasteless nature of 1080 , while being a danger if made available to all and sundry, was one of its appeals. The bitterness of strychnine was one of the reasons rabbits often refused to take poisoned bait. Regarding to the cost, the price of 1080 was approximately $8 /$ - per oz while strychnine was $14 /$ - per oz and $14 /$ - worth of 1080 would be sufficient to poison $49 \mathrm{lbs}$ of pollard or apples but one oz of strychnine would be sufficient to poison only $40 \mathrm{lbs}$. In addition, a farmer near Launceston had offered to allow a trial on his property if 1080 could be obtained (TGAM).

On 21 August 1950 Meldrum sent two memos to Hughes, the first to say that he was applying to the Director, Veterinary Hygiene in Canberra for permission to import 1080 for trial purposes, and suggesting that thallium sulphate be also trialled at various strengths. This had been used by the Chief Inspector of Health to kill rabbits in the Rokeby area near Hobart with an excellent kill recorded. The second memo reported on a U.S. Fish and Wildlife Technical Advice relating to the use of coloured baits to repel birds. This report presumably was based on the paper published by Kalmbach \& Welch (1943), and indicated that Keith Meldrum was already considering the possibility of protecting birds from being poisoned (TGAM).

No objection to the import of 2 lbs of 1080 was raised by the Commonwealth Director General of Health, leaving the way open to carry out trial work in Tasmania. An approach to ICI in Hobart, as Monsanto agents, to purchase the 1080 resulted in a requirement for the Department of Agriculture to acknowledge in writing that it realised the toxicity of this material, understood the risks involved and had read pamphlets supplied by the company. This reflected the earlier agreement between the US Government and Monsanto (TGAM).

Meldrum wrote to Francis Ratcliffe of the CSIR in November 1950 to say that the Department of Agriculture had sought approval to import 1080 , was also interested in thallium sulphate and asked for any information on other poisons, decoys (lures) or baits. In reply, Ratcliffe noted that the CSIR was trialling new poisons and that 1080 was promising as it was well accepted by rabbits and was effective. He thought thallium sulphate was not likely to be of much use due to its low toxicity and high cost and ended by suggesting that it would be a good idea to plan their research programs together when he had a man in place in the team whose special job would be the field investigation of poisons (TGAM).

The 1080 finally arrived in November 1951 and Keith Meldrum arranged to procure 20 rabbits to allow the 
determination of the minimum lethal dose, the amount needed to kill all of a group of animals $\left(\mathrm{LD}_{100}\right)$. This test resulted in a calculated value of approximately $1 \mathrm{mg} / \mathrm{kg}$ body weight, compared with a value of approximately 0.8 $\mathrm{mg} / \mathrm{kg}$ later published by Lazarus (1956) based on the work referred to by Ratcliffe (TGAM).

In early February 1952 a series of trials was initiated to field test 1080 bait, with Jeff Bignell, a Department of Agriculture veterinary officer, in charge. The first trial in a netted paddock at Bothwell was to test a range of baits, so apples, pollard and jam, pollard and sugar and pollard and dehydrated apple waste were used as free feed. Apples were used on two miles $(3.2 \mathrm{~km})$ of the furrow and the remaining baits were equally spread over another mile. Apples were taken in preference to any other bait and as a result, the area which had been free-fed with apple was poisoned with apple containing approximately $0.1 \% 1080$ from powder. The results were initially disappointing with only $5-10 \%$ of the bait taken and few rabbits found dead. A thorough search of the area, however, resulted in 216 rabbit carcasses being picked up and after excavating a few burrows it was evident that many more had died. About 40 more carcasses were found in the following fortnight as rabbits ate the remaining bait.

The second trial, also at Borhwell, was to determine the effectiveness of 1080 in a pollard mix similar to that used in a poison cart, a trailer used to lay baits automatically. Pollard and jam was compared with pollard, sugar and dehydrated apple waste $(10: 1: 1)$ at a range of 1080 concentrations. The bait was laid in a 5 -mile $(8-\mathrm{km})$ long furrow around a crop and was a failure with little bait taken, but no free feeding appeared to have been carried out prior to the poisoning. A subsequent strychnine poisoning and trapping on the same furrow yielded 4000 rabbit carcasses.

In the third trial, near Ouse, 1080 was first mixed into a solution and then applied to bait at concentrations of $1 \mathrm{oz}$ of 1080 to $28,56,112,168$ and $224 \mathrm{lb}$ carrot $(0.22,0.11$, $0.056,0.037$ and $0.028 \% 1080$ ). This was to test carrot instead of the traditional apple bait and to see whether bait shyness occurred at the higher concentrations. All concentrations were taken well and the "result left nothing to be desired and the owner's satisfaction in the kill was matched only by his chagrin at being unable to obtain $10 \mathrm{lbs}$ of 1080 " (J. Bignell internal file report, April 1952, TGAM).

As the previous trials had been carried out in dry conditions, traditionally the best time for rabbit poisoning because there is little alternative feed available, the fourth 1080 trial was carried out in the highlands in April in an area with green feed. Free feeding had been carried out inadequately, and as a consequence rabbits were not well attracted to the bait. Although at least $90 \%$ of the $4 \mathrm{cwt}$ $(200 \mathrm{~kg})$ of apple bait with a 1080 concentration of 1 oz/cwt $(0.056 \%)$ was eaten, the percentage kill did not appear to be very good.

The area chosen for the next trial had difficult conditions for rabbit control. A deep gorge ran through the 2000 -acre (800-ha) block, and the whole area had been poisoned twice with phosphorus and once with strychnine, the latter only eight days before the 1080 baiting when 630 dead rabbits were collected. Apple bait was used at $1 \mathrm{oz} / 160 \mathrm{lb}$ apple $(0.039 \%)$. More than $3 / 4$ ton $(870 \mathrm{~kg})$ of bait was used and 1500 rabbits were picked up with many more crow-picked carcasses left to decay. The local rabbit inspector accompanied by his dog saw only four live rabbits during a subsequent inspection (TGAM).
The final in this group of trials was in May 1952 to compare apple bait with boiled oats. Initially apples were taken better, but following rain the oats became more palatable. This trial used the, by then, standard 1080 concentration of $0.039 \%$. Before the final trial Keith Meldrum, among others, must have been convinced of the effectiveness of 1080 because in early May 1952 he contacted Monsanto Chemicals in Victoria for a quote on $100 \mathrm{lbs}$ of 1080 to be used in the following 12 months. By the end of May Alan Hughes reported that farmers were applying to have the Department lay 1080 on their properties. On 25 June the Secretary for Agriculture asked the Supply and Tender Department to order $200 \mathrm{lbs}$ of 1080 , with $15 \mathrm{lbs}$ being airfreighted for use in the current season. A firm order was placed with Monsanto at the end of July, but the Commonwealth Customs would issue an import permit for only $15 \mathrm{lbs}$ as the remainder was thought to be in excess of Tasmania's normal needs. Keith Meldrum, via the Secretary for Agriculture and the Manager of the Supply and Tender Department questioned the Customs department's ability to assess the need for 1080 , a new poison, and pointed out that the $200 \mathrm{lbs}$ would be 12 months' supply. Customs was not convinced by the argument and it was only when the Tasmanian Minister for Agriculture and Senator Wordsworth raised the issue with the Commonwealth Minister for Trade and Customs that the permit was issued in January 1953. The airfreighted $15 \mathrm{lbs}$ arrived in February to allow poisoning to begin in earnest, although a small amount had been borrowed from the CSIRO in the meantime to allow work to continue (TGAM).

Once the Department had decided on 1080 for rabbit control, Keith Meldrum wrote to the Chairman of the Pharmacy Board (10 July 1952) suggesting that some control over its use be implemented because of its toxicity, solubility and lack of taste, colour or antidote. The Pharmacy Board, however, considered that as agricultural and horticultural bodies were exempt from the Poisons Act, the use of 1080 should be controlled by the Stock Medicines Board and as Monsanto would only sell to Government agencies, there was sufficient control already (TGAM).

In July Francis Ratcliffe wrote to Meldrum to say that their results with carrot bait had been similar to the Tasmanian experience and it was probably the best bait to use with 1080. In the same month Alan Hughes began to train the Vermin Destruction Team in 1080 poisoning techniques (TGAM).

In September 1952 interest was expressed in 1080 trial results by the New Zealand Department of Agriculture which had not previously encouraged its use because of the risks to livestock (TGAM).

Francis Ratcliffe wrote to Meldrum in February 1953 suggesting that because his section and the Tasmanian Department of Agriculture were both conducting 1080 trials, they should have a policy for 1080 use which should be strictly adhered to by anyone using the material. In his reply, Meldrum reinforced the fact that 1080 would be sent out to field officers as a liquid for incorporation into bait and would probably be coloured blue, a practice finally implemented over 30 years later (Statham 1987), although either fluorescein (yellow/green) or nigrosin (black) were used to colour the 1080 in the intervening period (TGAM).

With the arrival of the 1080 another training day was held near Ross in February 1953 to ensure the field staff were fully conversant with its use. This training day was also attended by Ian Rowley, a CSIRO scientist who had 
just started working in Tasmania on rabbit behaviour and baiting techniques, an area of research Ratcliffe had seen as necessary in 1949. Charges for labour and materials were set and a circular for landholders wanting to apply for 1080 use on their property produced and circulated (TGAM). The field poisoning techniques used were those described by Meldrum et al. (1957).

There were excellent results with rabbit control. For example, in April 1953 a letter from a farmer near Penguin to the Devonport Vermin Officer stated "I have done a considerable amount of poisoning with strychnine with apples and swedes in the past. Although good kills have been obtained the rabbit population has not been reduced to such an extent as to be visible to the eye. However after using 1080 the visible decrease in rabbits is outstandingly obvious. Where 50 rabbits were visible round a warren not one is now seen. A fortnight after poisoning I walked over the property to see its effect and saw only two rabbits where hundreds were sighted previously".

It was not long before problems began to occur, with 33 sheep being poisoned in March 1953 when an area was restocked four days after poisoning. An inspection revealed the uneaten bait had not been well covered and there was little other feed available. Problems with non-target kills continued, and in June 1953 Keith Meldrum requested all vermin officers to provide information on the nontarget kills in their areas (TGAM). The recorded deaths in domestic animals (table 1) indicate that landholders were ptobably treating 1080 as they had strychnine in relation to removal of uneaten bait. Strychnine has a toxic dose for

TABLE 1

\section{Non-target kills reported March-June 1953}

\begin{tabular}{lr}
\hline Horses & 1 \\
Cattle & 9 \\
Pigs & 1 \\
Sheep & 490 \\
Dogs & 31 \\
Cats & 26 \\
Deer & 6 \\
Kangaroos & $100+{ }^{*}$ \\
Possum & 47 \\
Bandicoot & $20+$ \\
Starlings & large nos \\
Black birds & large nos \\
Parrots, crows, wren, plover, fantail & few of each \\
\hline
\end{tabular}

* Primarily in the Royal George area sheep of $8 \mathrm{mg} / \mathrm{kg}$ (Hone \& Mulligan 1982) compared with $0.4 \mathrm{mg} / \mathrm{kg}$ for 1080 (Annison et al. 1960, Hone \& Mulligan 1982) and it was therefore more important to remove or bury residual poisoned 1080 baits.

There are no data available on the non-target effects of strychnine or phosphorus because Government inspectors were not involved in its use and there was no requirement for anyone to keep records. It would be expected that the non-target effects of the earlier poisons would be greater because the range in $\mathrm{LD}_{50}$ values for different animal groups is lower than 1080 (table 2) hence more would be at risk of poisoning if they ate the bait. In particular, the low $\mathrm{LD}_{50}$ for birds would indicate that they would at risk of being killed by apple-based strychnine baits.

The term $\mathrm{LD}_{50}$ refers to the lowest dose that should be expected to kill $50 \%$ of the animals that received it (Weil 1952). It is a statistical value used to compare the effect of a chemical on different species or different chemicals on the same species, compared to the minimum lethal dose $\left(\mathrm{LD}_{100}\right)$ which is the amount needed to kill all of a group of animals.

By the beginning of July more than 100 of the $200 \mathrm{lbs}$ of 1080 had been used and Keith Meldrum warned the Secretary that they would need another $100 \mathrm{lbs}$ by February 1954, resulting in an order for $200 \mathrm{lbs}$ being placed with Monsanto (TGAM).

In order to find accurate figures for the effectiveness of 1080 two trials were conducted inside netted paddocks. These trials and the results are described in Meldrum et al. (1957). Essentially the first trial resulted in $88 \%$ of breeding does being killed but many 3-5 week-old young survived, while in the second, in a non-breeding period, there was over $95 \%$ mortality. This reinforced the ideas that 1080 was superior to strychnine and phosphorus (TGAM).

In the first half of 1954 there was interest from other jurisdictions in the results of 1080 poisoning in Tasmania, including requests for information on 1080 rabbit poisoning from the Ministry of Agriculture and Fisheries in the United Kingdom; Vermin and Noxious Weed Branch, Department of Crown Lands Victoria; and the Director of Agriculture in New South Wales. Victoria and Western Australia had already begun rabbit control trials with 1080, but the Chief Vermin Control Officer from Western Australia, A.R. Tomlinson, wrote asking for information on the practical arrangements for rabbit control with 1080 including charging, costs and the effectiveness of the Tasmanian staffing procedures. Western Australia set up a mobile team system in 1955 which was similar in most respects to the Tasmanian system (Tomlinson et al. 1956). The Secretary of the New Zealand Rabbit Destruction Council also requested that two staff

TABLE 2

$\mathrm{LD}_{50}(\mathrm{mg} / \mathrm{kg}$ body wt) of strychnine, phosphorus and 1080 in different animals

\begin{tabular}{lllcc} 
& \multicolumn{1}{c}{ Species } & Strychnine & Phosphorus & 1080 \\
Introduced carnivore & Dog & 0.75 & $3-6$ & 0.07 \\
Introduced omnivore & Pig & $0.5-1$ & $1-6$ & 0.4 \\
Introduced herbivore & Rabbit & 0.6 & 4 & No data \\
Native herbivore & Tas. pademelon & No data & No data & No data \\
Native carnivore & Tas. devil & No data & No data & 9.13 \\
Bird & Wedge tailed eagle & No data & No data & $5.6-8.6$ \\
Bird & Mallard duck & 2.9 & 2.2 & 54 \\
Amphibian & Bull frog & & & \\
\hline
\end{tabular}

Data from Hone \& Mulligan 1982, Mcllroy 1981, Mcllroy 1982, Mcllroy 1984. 
be allowed to visit Tasmania to study the work on 1080 . I. Carney, a veterinary officer and A. Forrester, a Principal Rabbit Inspector, arrived in late October for a 10-day visit (TGAM).

During this period there was a number of letters to the editors of the local papers complaining about the effects of this new poison on native wildlife, deer and dogs. Interest in the issue seemed to wane when Dr Eric Guiler from the University of Tasmania was reported in June as having told a meeting of the Animals and Birds Protection Board that it was not as great a threat to native animals as snares used for rabbit trapping or strychnine. "A smear campaign had been conducted against use of this poison", he said, "and incredible stories of its effectiveness were being circulated" (Mercury 23 June 1954).

The new order for 1080 from Monsanto ran into trouble in July 1954 when the Department of Trade and Customs refused to allow the import from America. Another company, Associated Fumigators in London, was reported to be producing 1080 and under the United Kingdom and Australia Trade Agreement 1932, goods had to be sourced in Britain if possible. Enquiries to Associated Fumigators revealed that it produced sodium fluoroacetate and also another named fluoracetamide, $5 \mathrm{lbs}$ of which was ordered in August for trials. Fluoracetamide had been shown to be highly toxic in early British work (McCombie \& Saunders 1946), and had been given the code 1081 in the USA. In Tasmania, however, it was called 1066. This material was claimed by Associated Fumigators to be more acceptable to rodents and cheaper to produce than 1080. An enquiry to Francis Ratcliffe revealed that he knew about fluoracetamide, had been considering getting some for trials but was delighted to leave the preliminary trials to Keith Meldrum and his colleagues (TGAM).

Towards the end of 1954 there were differences between the states in their attitude to 1080. Tasmania, Western Australia and Victoria had carried out trials and were providing a service to landholders. New South Wales had carried out a trial at Trangie and in a memo to all veterinary officers and Inspectors of Stock the Chief of the Animal Industry Division commented that it would be unlikely to be introduced to NSW. The reasons were the trial had shown 1080 was no better than strychnine and the author speculated that 1080 use would be likely to result in the loss of a great deal of wildlife. The Department of Health also objected because of the serious effect it could have on humans. In Queensland, according to the United Graziers Association, who wanted to use 1080 for dingo control, the Director-General of Health refused to release the material under any circumstances. The Sourh Australian Department of Health was discussing allowing the use because they had applications for permits which were necessary under their legislation and requested information on the results in Tasmania. Keith Meldrum replied to the NSW memo with the Tasmanian experience which negated the claims. He also, supplied SA with the information they wanted, as he had with any group or individual who requested information (TGAM).

Victoria went further and in September introduced a regulation under the Health Act setting conditions for 1080 bait preparation and use, but also allowing the sale of 1080 powder (Sodium fluoroacetate (Compound 1080) Regulations 1954). Alan Hughes raised the question of this 1080 reaching Tasmania and Keith Meldrum asked for more information from Victoria, particularly as to how they could get around the Monsanto requirement for it to be used by government agencies only. The answer was that Victoria was supplied with 1080 by Associated Fumigators which had no such restriction. In addition, the Superintendent of the Vermin and Noxious Weeds Branch replied that its inspectors were supplying poisoned bait to landholders, a practice not used in Tasmania, but that he hoped that in one or two years landholders would obtain supplies of 1080 directly without going through their department.

Meldrum suggested to the Pharmacy Board that they might like to reconsider their ideas on declaring 1080 a poison as it would soon be freely available in Victoria and could make its way to Tasmania. In January 1955 the Board did reconsider and agree to include 1080 as a poison and Meldrum then suggested that fluoracetamide should also be included as both were potentially available. In February Alan Hughes reported rumours of 1080 powder being imported to Tasmania, and this was passed to the Pharmacy Board by Keith Meldrum, but it was not until August 1956 that the two compounds were included in the new Poisons Schedule to provide some control over their sale and to prevent illegal importation of 1080 from Victoria (TGAM).

In March 1955, 2 of the $5 \mathrm{lbs}$ of fluoracetamide were delivered and again Jeff Bignell was given the job of trialling it. In May and June he showed that the minimum lethal dose for rabbits was similar to 1080 and there was no difference in acceptability. He also found that $1 \mathrm{oz}$ to 25 lbs $(0.25 \%)$ of wheat was effective on native hens, Gallinula mortierii, a pest in young crops, but suggested it would be too dangerous to adopt on a large scale for that use (J. Bignell internal memorandum to J. Green, Deputy Chief Veterinary Officer, 28 June 1955, TGAM). In a trial in August with 1080 and 1066 compared in alternate half-mile $(800-\mathrm{m})$ strips over a 13 -mile $(21-\mathrm{km})$ poison furrow he found that more 1066 was taken by rabbits and attributed it to the slower action allowing greater intake. Bignell considered that the slower action more than compensated for the increased poison needed. In reporting the results to Francis Ratcliffe, Meldrum suggested that fluoracetamide could replace 1080 as its slower action could minimise bait shyness. It was not, however, adopted and no more appears to have been purchased (TGAM).

In September 1955 interstate problems again arose when Pesticides Ltd in South Australia began selling 1080 oat bait with $1 \mathrm{oz}$ of 1080 per $125 \mathrm{lbs}$ of oats (0.05\%) and had agreement with several Tasmanian retailers to stock it. This oat bait was on sale in the state until a change to the Poisons Act in 1959 tightened the controls on both 1080 and fluoracetamide.

The final significant event occurred when Alan Hughes was invited to conduct training schools for New South Wales Pastures Protection Board officers in early 1959. The Department of Agriculture in that state was planning a statewide rabbit control campaign in the autumn of 1959 using 1080 . This was delayed by the inspectors being involved in control of a locust plague, but Hughes finally spent three weeks in NSW in June (TGAM).

From that time there were few significant changes to rabbit control practices in Tasmania. The early 1960s saw a big increase in rabbit numbers, during the low rainfall years (fig. 1) and by 1964 there were 25 Department of Agriculture staff, 17 Forestry Department staff and one Lands and Survey officer trained and authorised to hold stocks of 1080 solution to be used for rabbit control using the techniques developed in early trials (TGAM). 
The Tasmanian rabbit control scheme based on the use of 1080 was developed essentially by two people and had influences on practices in several other states. Francis Ratcliffe summarised the situation well when he wrote in a letter to Keith Meldrum in 1957: "your scheme hinged very heavily on the personality of one or two people (notably Alan and yourself) and if, in the course of events, less satisfactory key personnel had to be substituted, the efficiency of the machine would suffer".

Following this period a few changes in the use of 1080 occurred. They included the reduction in concentration of 1080 on bait, first from 0.038 to $0.02 \%$ based on the research of Ian Rowley (Rowley 1960) and later to the current $0.014 \%$ and the complete replacement of apple with carrot as bait to reduce the attractiveness to birds.

The reduction in rabbit numbers as a result of poisoning and myxomatosis led to greater investment in pasture development and a subsequent increase in populations of wallaby and possums (A. Morrison, pers. comm. to $\mathrm{H}$. Statham). Deliberate, rather than accidental, poisoning of wallabies was certainly being carried out by 1956, when 49 landholders on Flinders Island were given permits by the Animal and Plant Protection Board to poison wallabies and kangaroos. Later, control of these species in agricultural and forest areas with 1080 has led to much of the public concern about its use and contributed to the change from its ready acceptance in the 1950 s to the current plan to phase it out.

Probably the most prophetic comment about 1080 use was made in an internal US Government report by one of the early researchers on control of coyotes when he wrote about 1080: "It does not at present have thallium's bad name, but if not properly handled 1080 might acquire a reputation fully as bad if not worse" (Robinson 1945, cited by Connolly 2004).

\section{REFERENCES}

Annison, E.F., Hill, K.J., Lindsay, D.B. \& Peters, R.A. 1960: Fluoroacetate poisoning in sheep. Journal of Comparative Pathology 70: 145-155.

Atzert, S.P. 1971: A review of sodium monofluoroacetate (Compound 1080), its properties, toxicology, and use in predator and rodent control. United States Department of Agriculture Special Scientific Report - Wildlife, No. 146.

Barnes-Keoghan, I. 2002: Climate Statistics of Tasmania, State of the Environment Tasmania, Background Technical Report. Resource Planning and Development Commission, Tasmania.

Community Leaders Group, 2001: Tasmania Together plus Government activity reports. Tasmania Together, Hobart, Tasmania.

Connolly, G. 2004: Development and use of compound 1080 in coyote control, 1944-1972. In Timm, R.M. \& Gorenzel, W.P. (Eds). 21st Vertebrate Pest Conference. Visalea, California: 221-239.

Hone, J. \& Mulligan, H. 1982: Science Bulletin 89 Vertebrate Pesticides. Department of Agriculture New South Wales.

Hughes, A.E. 1959: Rabbit control in Tasmania: Field Procedure. The Rabbit Problem in Australia. CSIRO, Melbourne: $27-33$.

Kalmbach, E.R. 1945: "Ten eighty" a war-produced rodenticide. Science 102: 232-233.

Kalmbach, E.R. \& Welch, J.G. 1943: Colored rodent baits and their value in safeguarding birds. Journal of Wildlife
Management 10: 353-360.

King, J.E. \& Penfound, W.T. 1946: Effects of new herbicides on fish. Science 103: 487.

Lazarus, M. 1956: The toxicity and relative acceptability of some poisons to the wild rabbit, Oryctolagus cuniculus (L) CSIRO Wildife Research 1: 96-100.

McCombie, H. \& Saunders, B.C. 1946: Fluoroacetates and related compounds. Nature 158: 382-385.

McIlroy, J.C. 1981: The sensitivity of Australian animals to 1080 poison. II Marsupial and eutherian carnivores. Australian Wildlife Research 8: 385-400.

McIlroy, J.C. 1982: The sensitivity of Australian animals to 1080 poison. III Marsupial and eutherian herbivores. Australian Wildlife Research 9: 487-504.

McIlroy, J.C. 1984: The sensitivity of Australian animals to 1080 poison. VII Native and introduced birds. Australian Wildlife Research 11: 373-386.

Meldrum, G.K. 1959: Rabbit control in Tasmania: Design and administration. The Rabbit Problem in Australia. CSIRO, Melbourne: $17-26$.

Meldrum, G.K., Bignell, J.T. \& Rowley, I. 1957: The use of sodium fluoroacetate (Compound 1080) for the control of the rabbit in Tasmania. Australian Veterinary Journal 33: 186-196.

Nichols, H.C., Thomas, E.F., Brawner, R.W. \& Lewis, R.Y. 1949: Report of poisoning two dogs with 1080 rat poison (sodium fluoroacetate). Journal of the American Veterinary Medical Association 15: 355-356.

Rolls, E.C. 1969: They All Ran Wild. Angus and Robertson, Sydney.

Rowley, I. 1960: The effect of concentration on the ingestion of "1080" - poisoned baits by the rabbit. CSIRO Wildlife Research 5: 126-133.

Statham, M. 1987: Dyed baits for wallaby control. In Merryll, P., Smith, M. \& McKenna, J. (Eds). 8th Australian Vertebrate Pest Control Conference. Queensland Rural Lands Protection Board, Coolangatta, Queensland: 387-391.

TGAM (Tasmanian Government Archived Marerial) AD9 Files 8/2D Vermin destruction - Rabbit Poisoning and Poison Supplies from the years (1949-50), (1951-52), 8/2D. Vermin Destruction - Poisons and Poison Supplies, from the years (1953-54), (1955-56), (1957-58), (1959-63), (Jan 1964 - Dec 1969), and AD 9 File 08/6 (1) Vermin Destruction - Methods of Vermin Control, 1-Nov-1959 to $31-\mathrm{Dec}-1983$.

The Advocate newspaper (Burnie) references as cited in the text.

The Examiner newspaper (Launceston) references as cited in the text.

The Mercury newspaper (Hobart) references as cited in the text.

Tomlinson, A.R., Marshall, C.E. \& Gooding, C.D. 1956: The new approach to rabbit poisoning "1080" and improved methods. Journal of Agriculture Western Australia 5: 5-16.

Ward, J.C. 1946: Rodent control with 1080, ANTU, and other war-developed toxic agents. American Journal of Public Health 36: 1427-1431.

Ward, J.C. \& Spencer, D.A. 1946: Notes on the pharmacology of sodium fluoroacetate - Compound 1080. American Pharmaceutical Association Journal 36: 59-62.

Weil, C.S. 1952: Tables for convenient calculation of median effective dose (LD50 or ED50) and instructions in their use. Biometrics 8: 249-263.

Williams, A.T. 1948: Sodium fluoroacetate poisoning. Hospital Corps Quarterly 21:16-18.

Williams, C.K., Parer, I., Coman, B.J., Burley, J. \& Braysher, M.L. 1995: Managing Vertebrate Pests: Rabbits. Bureau of Resource Sciences/CSIRO Division of Wildlife and Ecology. Australian Government Publishing Service. Canberra.

(accepted 27 June 2005) 